\title{
Students of Poznan University of Medical Sciences are not enough prepared to provide high quality basic life support
}

\author{
Tomasz Kłosiewicz' Michał Mandecki', Ilona Skitek-Adamczak', Radosław Kadziszewski² \\ ${ }^{1}$ Department of Rescue and Disaster Medicine, Poznan University of Medical Sciences, Poland \\ ${ }^{2}$ Student Scientific Circle of Medical Simulation, Poznan University of Medical Sciences, Poland
}

\begin{abstract}
Introduction. In case of sudden cardiac arrest (SCA) quick recognition and provision of immediate high quality cardiopulmonary resuscitation (CPR) increases chance of survival. It has been proven that Poles' knowledge about the basic life support is insufficient. Alumni of medical universities are expected to have practical skills and extensive knowledge to provide appropriate help to SCA victim.

Materials and Methods. This was a descriptive, cross-sectional study. We invited all Polish-language students of Poznan University of Medical Sciences (PUMS). 434 people took part in the survey. The research tool was online questionnaire containing 20 questions.

Results. Most of correct answers was given by students of Medical Faculty I, then Faculty of Health Sciences, Medical Faculty II and Faculty of Pharmacy (median of correct answers as follows: 9.48, 8.86, 7.90, 6.93). The biggest problem our students had with questions about: time of interruptions in chest compressions, depth of compressions and duration of a single breath (respectively: $27.63 \%, 36.53 \%, 38.64 \%$ of correct answers). $42.56 \%$ of students would initiate CPR if they saw agonal breaths. 34.50\% percent believed that they are properly prepared for CPR while $60.05 \%$ said that the number of first aid course hours is insufficient. We found statistically significant relationship between number of critical mistakes and faculty of study $(p=0.00003$, contingency factor $=0.2282$ ).

Conclusions. The knowledge of PUMS students about CPR is inadequate. It is suggested to evaluate the number of hours dedicated to CPR classes. We should pay attention to identifying agonal breaths and all the criteria of CPR quality.
\end{abstract}

Keywords: cardiopulmonary resuscitation; knowledge; students.

\section{Introduction}

The data concerning Poles' mortality collected by the Central Bureau of Statistics had showed that leading cause of death in Poland are cardiovascular diseases which constitute $46 \%$ of all deaths. The sudden cardiac arrest (SCA) that is a result of dysfunction of the cardiovascular system is a direct cause of death [1]. Early SCA recognition and implementation of cardiopulmonary resuscitation (CPR) to the victim triples the chances of survival and reduces the risk of complications connected with the central nervous system (CNS) caused by hypoxia. Existing Polish regulations impose on each bystander obligatory provision of first aid (FA) to any person in life threatening situation. These regulation are included in both The State Traffic Code and the Act of State Medical Rescue. Currently FA trainings are widely available to citizens. Previous studies have reported that most extensive knowledge have young people living in large cities and having a higher education [2]. However, several observations have indicated a lack of knowledge about CPR among Polish society $[3,4]$. Special expectations the society directs towards 
healthcare providers as well as students of medical universities. This means in particular that these people should be able to adequately respond, quickly and effectively act, when life threatening situation appears. European Resuscitation Council (ERC) in the "Guidelines for Resuscitation 2010" presented basic life support (BLS) algorithm and described its correct execution, such as assessment of patient's condition, opening the airway, rescue breaths, chest compressions and use an automated external defibrillator (AED). Clear criteria for chest compressions quality, which are the most important part of CPR have also been defined. The updated guidelines from 2015 upheld these recommendations. The discussed indicators of quality are: rate and depth of compression, correct hands position and full recoil after each compression. Rescuers should switch every two minutes to avoid fatigue. It has been proven that the failure to meet these criteria causes low quality actions which entail inadequate perfusion and thus reduces the chances of survival. Chest compression should be given immediately. Beginning CPR in more than four minutes of the onset of SCA is associated with a poor outcome [5]. The Poznan University of Medical Sciences (PUMS) educates students in four faculties: Medical I (MF I), Medical II (MF II), Faculty of Pharmacy (FPh) and Faculty of Health Sciences (FHS). The training leads to BSc, MSc, MD, DDS and Pharm. D. degrees. The number of hours provided for education in helping people in life-threatening condition varies depending on the department and faculty. During classes, students gain knowledge and skills for dealing with emergencies, tailored to the level of future professional competence. Each training program regardless of the level of advancement includes a recognition of SCA and providing BLS. The central thesis of this paper is to examine the level of knowledge of students in the field of CPR and to compare that level in individual faculties. Part of the aim of this project is to answer to the question whether students feel adequately prepared to provide resuscitation. The authors believe that results of this study can improve the education in this subject.

\section{Materials and Methods}

The survey was conducted among 434 PUMS students in December 2015. The research tool was author's internet questionnaires addressed to students of Polish-language faculties. Five questionnaires have not been included for further analysis because of the lack of information. The results were elaborated in Statistica version 12 GB (analysis of statistical significance using Chi2 test, with level of alpha $=0.05)$. Charts and tables were prepared in Microsoft Office Excel 2007 (v12.0). For critical mistakes made by the respondents we considered wrong answer to at least one of three following questions. The first concerned the taking or not CPR to the victim when rescuer is in doubt about presence of normal breathing. The second - an indication of actions to be taken as a priority to the victim, who presents agonal gasps. While the third concerned the correct way to open the airway.

The cohort was diverse in terms of gender, faculty, field and year of study and the fact of being trained or no being trained in FA during academic education. Among 434 students participating in the study, most of the respondents were women (68.43\%). The group of men was significantly lower (31.57\%). The largest group of individuals were students of the MF I (39.16\%) next students of the FHS (38.93\%), MF || (11.19\%) and the FPh (10.72\%). According to field of study the largest group consisted of medicine students (39.16\%), next paramedic students (11.19\%) and nursing students (11.19\%). During the research, most respondents were studying on the first $(28.90 \%)$ and second $(28.90 \%)$, year. The vast majority $(88.11 \%)$ said that they had already been trained in FA during education on PUMS before felt out the questionnaire.

\section{Results}

The surveyed were asked the question, whether they think that they are well prepared to perform CPR if necessary. $34.50 \%$ stated that they are not adequately qualified. There was no statistical relationship between the feeling of being well prepared to responding and PuMs faculties ( $p=0.18704$ ). The detailed answers broken down into faculties are compared in Figure 1.

The questionnaire contained 14 questions that evaluated the knowledge. Among all respondents, the median of correct answers was 9 points (14.45\%), while the most common result was obtained at 8 points (16.32\%). $75 \%$ of students obtained a score of 11 points or less.

There has also been analyzed the number of correct answers, depending on the student's participation in a FA course, during education at PUMS. Average points scored among the people who haven't been trained was 6.96. The most common result obtained was 8 points $(27.45 \%)$, while $25 \%$ of respondents in this group received a score 8 points or higher. On the other hand, students who participated in the FA course, had the most frequently score of 9 points (16.18\%) and the average score was 9.03 points. $75 \%$ of respondents in this category achieved the result of 7 points or more. 


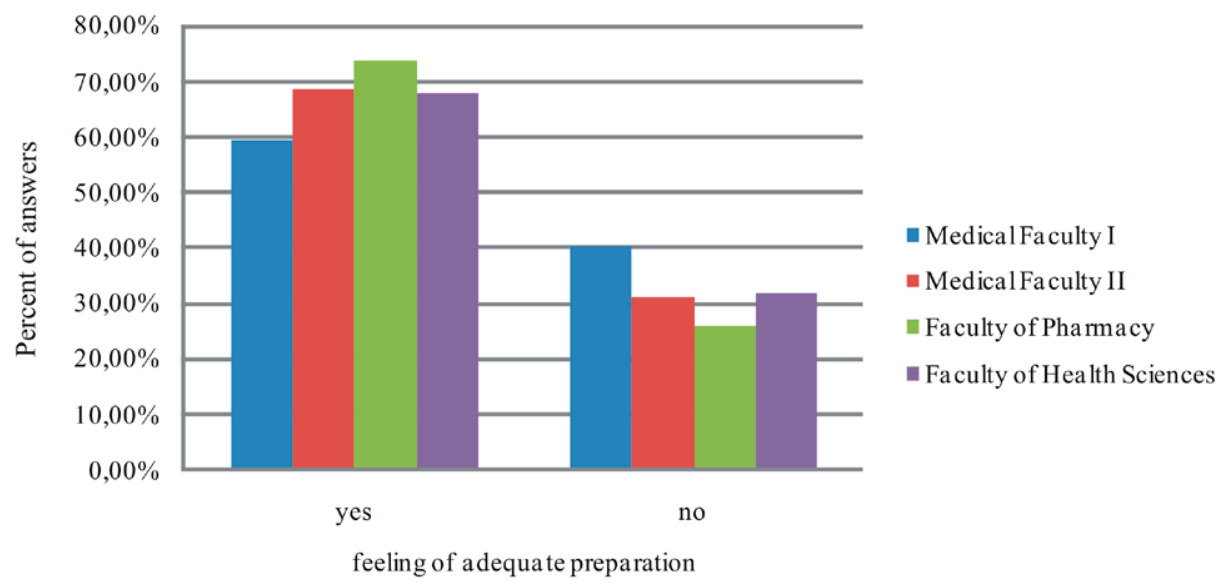

Figure 1. Answer for question: "Do you feel adequate prepared to provide BLS", depending on faculty

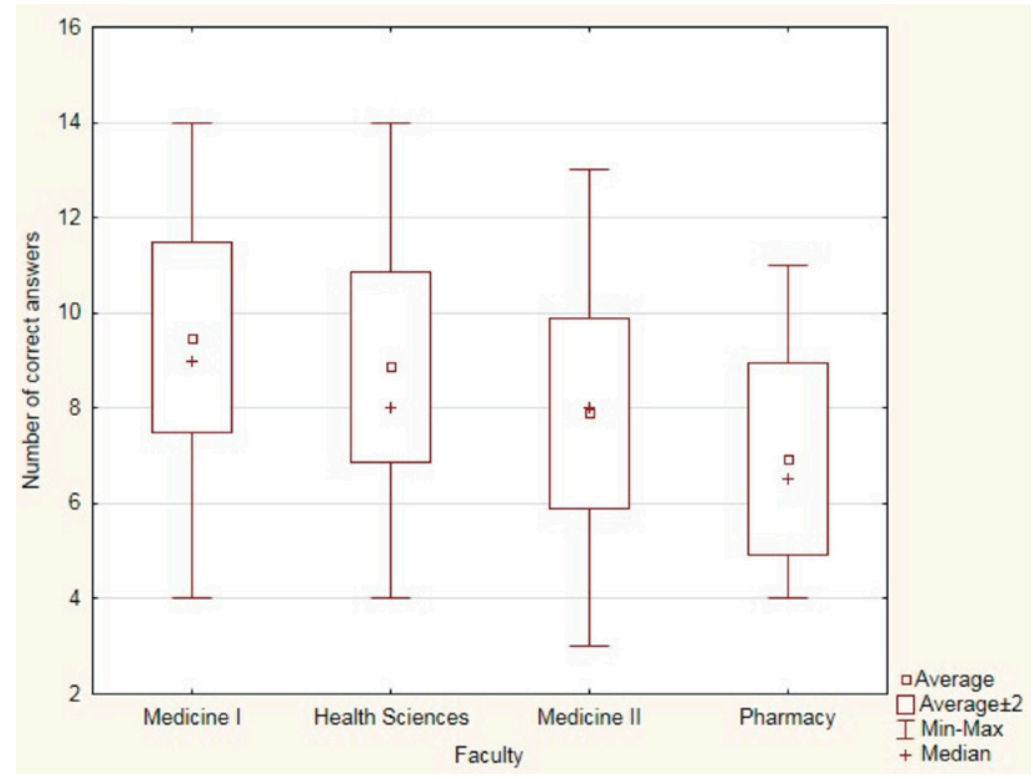

Figure 2. Number of correct answers given by responders, depending on faculty

When comparing number of correct answers depending on faculty, we received the highest average points from students of MF I (9.48 points), next of FHS (8.86 points), MF II (7.90 points) and FPh (6.93 points). Distribution of number of correct answers divided into faculties is presented in Figure 2.

In response to question, that concerned the appropriate behavior in case, when the rescuer see the collapsed person presenting agonal gasps, $42.56 \%$ of all scholars answered incorrectly that the victim should be placed in recovery position. The majority of incorrect answers was given by FPh students - 65.22\%, 49.98\% students of MF II, $45.51 \%$ students of FHS and $31.55 \%$ MF I. The correct answer, which was chest compression, was given most often by students of MF I (53.57\%), the least likely by students of FPh (19.57\%).
Then the participants were asked about the duration of breathing assessment. This parameter was known to most PUMS students $-85.45 \%$ of them pointed to a 10-second assessment. Among the departments the most correct answer was given by students of the MF I (91.62\%), then FHS $-83.73 \%$, FM II $-80.85 \%$ and FPh $-73.91 \%$.

Another question concerned the situation, when the rescuer is in doubt that the victim is breathing. Most of the students in all faculties correctly pointed out that in such a situation rescuer should begin CPR $(85.55 \%$ of all individuals). We haven't found a statistically significant difference between number of correct answers and PUMS faculty $(p=0.09070)$.

Respondents were also asked to indicate which emergency number would they prefer, if there it was 
a necessary to call for ambulance. In Poland we can seek medical assistance calling either 112 or 999 . Most students (67.83\%) would choose 999 number to call for help. This trend was most noticeable among students of FHS (80.84\%), next by students of FM II (68.75\%). Future physicians would choose 999 number in $58.33 \%$, and those studying at the FPh less likely did the same (54.35\%). By contrast 112 number was chosen less likely.

In next question we asked where the rescuer should put her or his hands to perform chest compressions during CPR $-54.08 \%$ of all students indicated, that in the middle of the sternum, which was incorrect answer. When dividing the results depending on faculties, the appropriate hands position (in the middle of the chest) was indicated most likely by students of FHS $-44.91 \%$, then MF I - 38.69\%. In contrast, only two of individuals did not marked correct answer, when asked about chest compression:ventilation ratio.

ERC Guidelines recommend that chest compressions during CPR should have a depth of at least 5 centimeters but not more than $6 \mathrm{~cm}$. Knowledge on this item had $36.53 \%$ of all respondents - the majority of correct answers we received from of MF I students(44.05\%) and FHS students (37.58\%).

Another crucial element of CPR is appropriate rate of chest compressions. This must be at least 100 per minute but no more than 120 per minute. This recommendation was not obvious for $28.26 \%$ of FPh students and $58.33 \%$ students of MF II, while MF I students pointed the proper answer in $73.65 \%$ of cases and the Faculty of Health Sciences in $64.67 \%$. There was no statistical significant difference between knowledge about the correct hands position and faculties ( $p=0.99294$ ).

The ERC Guidelines also strongly indicate that maximal time, without chest compressions that the rescuer may dedicate to ventilation is 10 seconds. This was known for $27.63 \%$ of all PUMS students. The most frequently incorrect answer shown by responders was 5 seconds. (MF I - 59.04\%, FHS - 67.07\%, MF II $52.08 \%$, FPh $-63.04 \%$ ).

On the other hand, information about the best method to open airway had $98.60 \%$ of the respondents (in all departments the percentage of correct answers ranged from $95.65 \%$ to $99.40 \%$ ). The proper volume of single rescue breath, which should cause chest rise was also well known to the individuals $(92.97 \%$ of correct answers). The lowest score was recorded among students of the MF II (85.42\%).

However, for question about duration of single rescue breath, only $38.64 \%$ of all respondents correctly answered that it should be 1 second. MF I students were less likely wrong (44.64\% correct answers), while FPh students were wrong most often $-8.70 \%$ appropriate indications.

According to the BLS algorithm, after 30 compressions the rescuer proceed to make two attempts of rescue breaths. Such knowledge showed approx. 50\% of students from all faculties. There was no statistically significant difference between knowledge of ventilation in CPR and faculties ( $p=0.99294$ ).

Then we asked individuals about their reaction to choking when the victim is still loud coughing and asking for help $-68.60 \%$ of the students indicated the correct procedure (MF I - 86.90\%, MF II - 61.22\%, $\mathrm{FPh}-58.70 \%$, FHS - 55.09\%).

According to the ERC Guidelines to maintain high quality of CPR rescuers should switch roles every 2 minutes to avoid fatigue - this knowledge had 53.72\% of the PUMS students. In a similar percentage correct answers were given by MF I (61.31\%) and FHS (59.28\%), Further, FPh students were the least accurate in this question (19,57\%).

Aside from checking technical knowledge students were asked about their opinion about duration of FA classes. $60.05 \%$ of those who took part in the survey stated the opinion that the number of hours of FA course is insufficient. Only $30.95 \%$ of respondents claimed that the number of hours is adequate. The results obtained from this analysis can be compared in

\section{Figure 3.}

Among all the questions we indicated for three, the most crucial. These questions did not evaluate only the knowledge of quality determinants but primarily the knowledge of elements that have directly impact on victim's survival. $38.93 \%$ of all respondents did not made any critical mistakes (FM I - 50.60\%, FHS - 37.13\%, MF II - 27.08\%, FPh - 15.22\%). In the other hand, $61,07 \%$ made one or more mistakes (FM I $-49.40 \%$, FHS $-62.87 \%$, MF II - 72.92\%, FPh - 84.78\%). Nearly half of all respondents from the PUMS (48.95\%) indicated a wrong answer in one critical question. Two critical mistakes was made by $11.66 \%$ of learners. Among the 429 people three critical mistakes were done by only two students - one from FHS and one from FPh. The least critical mistakes were committed by students of FHS, then MF I and MFII. The greatest number of crucial mistakes was reported among FPh students. We found statistically significant difference between number of critical mistakes and faculty $(p=0.00003$, contingency factor $=0.2282$ ). The differences between faculties are highlighted in Figure 4. 


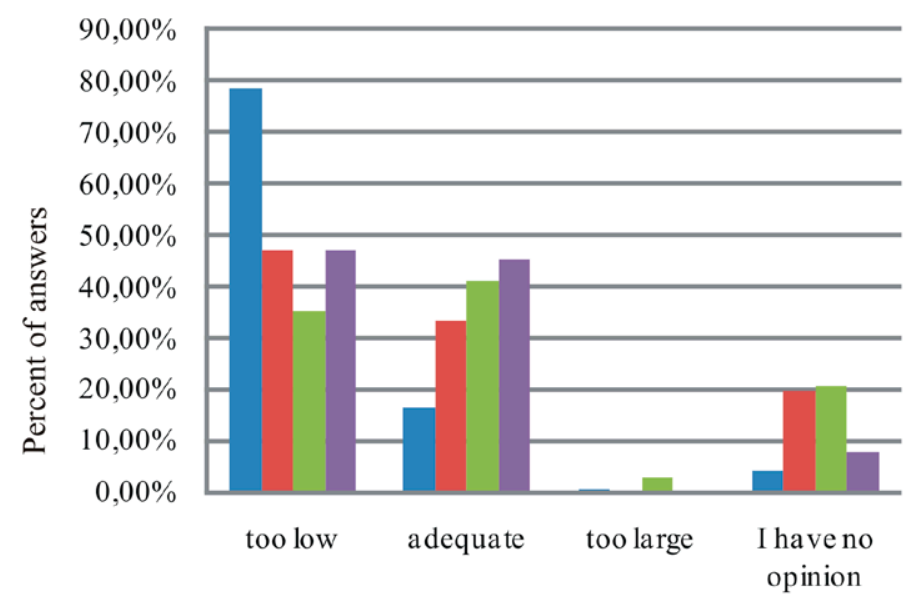

- MedicalFaculty I

- MedicalFaculty II

- Faculty of Pharmacy

- Faculty of Health Sciences

number of training hours

Figure 3. Opinion of students who have completed first aid course at Poznan University of Medical Sciences on the number of training hours, depending on faculty

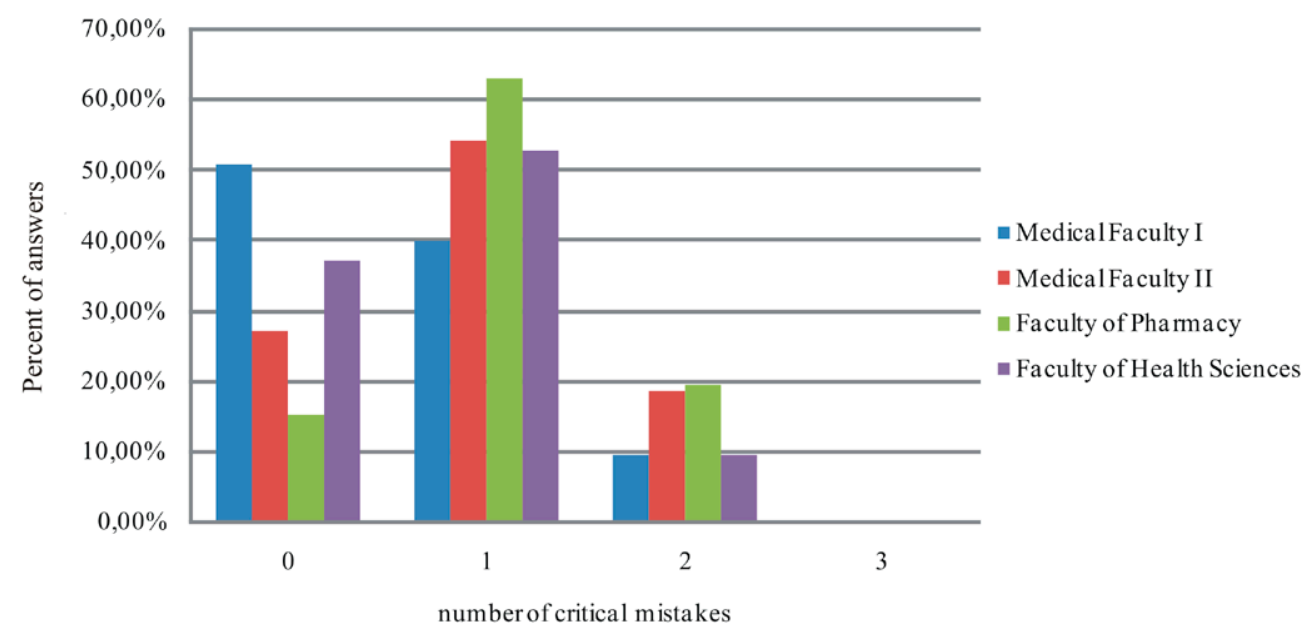

Figure 4. Number of critical mistakes that has been done by responders, depending on faculty

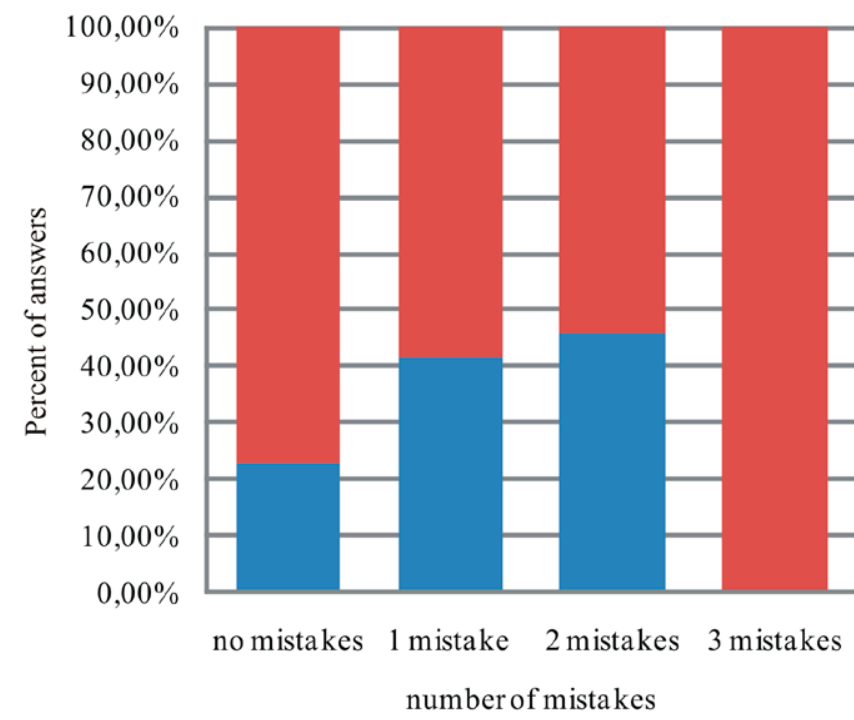

I feel well prepared to provide CPR

I do not feel well prepared to provide CPR

Figure 5. Number of critical mistakes compared with self-confidence 
The mistakes were done most commonly to the question about proceeding with casualty that is presenting agonal gasps (57.81\% of all incorrect answers). In case of doubt, whether the victim is breathing or not, students gave $14.45 \%$ incorrect answers. While the method of opening airway CPR was clear for the vast majority of respondents - reported $1.40 \%$ of the errors among all the people who fulfilled to the questionnaire. A statistically significant difference was found between the sense of proper preparation for giving CPR and the number of critical mistakes committed. Those who did not feel confident also did more errors (Figure 5). The results obtained from the analysis of the questionnaire are summarized in Table 1.
Only slightly more than $1 / 3$ of our students did not made mistake in any question concerning the implementation of interventions that are crucial for patients' survival such as taking CPR if agonal breaths are noticed or doubt about the presence of breath. Insufficient knowledge about agonal breaths that are associated with about $40 \%$ cases of SCA can be worrying whether future medics will be able to complete the first link in the chain of survival, which is to recognize life-threatening condition. Only the question about the correct method of opening airway was not an issue. The correct answer was given by $98.60 \%$ of the study group. A slightly weaker knowledge of this technique, was presented by researchers from India -

Table 1. Percent of correct answers for given questions

\begin{tabular}{lc}
\hline \multicolumn{1}{c}{ Issue } & $\begin{array}{c}\text { Percent of correct } \\
\text { answers }\end{array}$ \\
\hline Compression interruption no longer than 10 seconds & $27.63 \%$ \\
\hline Depth of compressions & $36.53 \%$ \\
\hline Duration of single rescue breath & $38.64 \%$ \\
\hline Appropriate reaction towards victim presenting gasping & $42.56 \%$ \\
\hline Correct action after 30 compressions & $50.00 \%$ \\
\hline Rescuers' switch time & $53.72 \%$ \\
\hline Correct hands position on the chest & $54.08 \%$ \\
\hline Rate of compressions & $60.43 \%$ \\
\hline Appropriate reaction towards choking preson & $68.60 \%$ \\
\hline Appropriate duration of patient's assessment & $85.45 \%$ \\
\hline Appropriate reaction, when have doubt on presence of the breath & $85.55 \%$ \\
\hline Volume of rescue breath & $92.97 \%$ \\
\hline Correct method to open airway & $98.60 \%$ \\
\hline Compression-ventilation ratio & $100.00 \%$ \\
\hline
\end{tabular}

\section{Discussion}

Our study referred to the level of knowledge about CPR among PUMS students. The University educates young people in different fields of medicine. The area of education is very wide. It assumes preparation to work both in occupations in which providing medical help to people with SCA is part of daily work, and those in which life-threatening situations are rare. Clearly, however, the ability to perform CPR should be known to every citizen and alumni of a medical universities are required to perform these tasks with due diligence and in accordance with the latest knowledge. Many studies have shown that the level of knowledge acquired during FA course has decreased over time [6-8]. According to previous, as well as the fact that the Guidelines are periodically updated, CPR courses should be repeated.
$81.7 \%$ of students knew the correct answer [9]. According to data collected by Pilip et al. [10] knowledge of the issue among Polish firefighters and lifeguards balanced from $57 \%$ to $92 \%$. However, such persons were not eligible as students in this study.

Among the determinants of the quality of CPR our responder had the lowest level of the knowledge that concerned the depth of chest compressions (only $36.53 \%$ gave the correct answer). A very low awareness of this parameter was also indicated by Alanazi et al. (15.8\% correct answers) [11]. In contrast to aforementioned findings, results of Olejniczak et al. can be suprising. They fonund that the correct answer on the depth of chest compressions was granted by $54 \%$ of study group (studies have been performed based on the ERC Guidelines 2010) [12]. 
Burkhardt et al. [13] showed that more than 93\% of the group correctly identified the rate of compressions. It is a surprisingly satisfactory result in comparison with our research (60.43\%). Skitek et al. [4] also found that percentage of PUMS students that properly defined the rate was $60 \%$. Another sources show the lack of knowledge as well: Alanazi et al. - 63.3\% [11], Chew et al. - 55.70\% [14] and Owojuyigbe et al. - 85.30\% of the students after training [15]. This study considered not only medical and nursing students but also emergency department workers and didn't specify the results for each group. It is interesting due to the fact that the researchers compared the obtained knowledge with the measurements obtained during practical exercises. They highlighted that the knowledge of guidelines has a significant impact on practical CPR skills, at least in terms of rate and hands position. Chemperek et al. [16], showed that only $24.4 \%$ of individuals granted the right answer on the rate of chest compressions in adults.

An important and also analyzed in this research aspect of CPR was to determine respondents' knowledge of depth of compressions. Unfortunately, most students (54.08\%) answered incorrectly, indicating that correct place is on center of the sternum, not on center of the chest. This result is better than in a similar study conducted by Chemperek et al. [16], where $62.8 \%$ of respondents gave wrong answer.

One unanticipated finding was that nearly $100 \%$ of our students were able to correctly identify appropriate compressions:ventolatio ratio. This is another very important component of CPR and our result puts our students in a good light compared with students from foreign universities, who gave the correct answer in 58.4\%, $72.9 \%$ and $97.1 \%$ [11, 14, 15], and also other universities in Poland, where the percentage of correct answers to this question was up to $72.6 \%$ in studies of Chemperek et al. [16], 85\% Olejniczak et al. [12] and 92\% of PUMS students in our previous study by Skitek et al. [4].

Comparing the different PUMS faculties we showed that the greatest knowledge had MF I students, then FHS, MF II and FPh. Attention should be drawn to the fact that the number of hours dedicated to BLS education varies considerably depending on the field of study. This number is as follows: paramedic students - 1035, physicians - 155 hours, dentistry - 140 hours, pharmacy and medical analysis - 45 hours, nursing and midwifery - 30 hours.

It does not change the fact that the knowledge of basic life-saving techniques should be sufficient regardless of the field of study. During education MF I students discuss issues several times during following courses: first aid, cardiopulmonary resuscitation, disaster medicine, emergency medicine, advanced medical simulation. We do not find surprisingly the fact of higher than in the other groups level of knowledge. It only serves to emphasize the value of CPR classes that are repeated.

The differences in the percentage of correct answers to individual questions can arise both from a different number of hours dedicated to teaching CPR at various universities and from the time that has elapsed from training to research. But despite their differences, all cited authors agree that the knowledge of students is insufficient.

The vast majority of our students (65.5\%) declared that feel properly prepared to provide CPR. At the same time a similar number of individuals felt that the CPR training is too short. Only FPh students pointed out that the training is sufficient - although they gave the least correct answers. In other studies done by Skitek et al., in which PUMS students participated, $68 \%$ of students declared good and very good CPR knowledge [4]. In study conducted by Olejniczak et al., only $53 \%$ of nursing students concluded that the knowledge they acquired during studies (and after graduation) is sufficient to effectively provide FA [12].

Our research has some limitations. We could not get a comparable number of students in all faculties. The most numerous students were involved in fields of which the graduates frequently have to deal with patients in life-threatening situations. These were the: paramedic, medicine, nursing, dentistry students. It certainly indicates a greater interest in emergency medicine subjects. Therefore, unfortunately, it can be expected that the obtained results might be overstated. We are also aware that the assessment of knowledge may not correlate with CPR skills. It is difficult to assess whether the knowledge of CPR is sufficient, when each of the studied aspects is very important and can affect the victim's chances of survival. We believe that our criteria of "critical errors" and "quality indicators" are a compromise in this difficult assessment.

We are curious to compare our students to other medical universities in Poland. We did not find, however, research conducted in our country, which cross-section profile of the study group and the evaluation criteria would allow to direct comparison with our results and draw the appropriate conclusions. This probably increases the originality of our work.

\section{Conclusions}

1. The level of PUMS students' knowledge is insufficient. 
2. It is suggested to evaluate or increase the number of hours dedicated to CPR classes. These activities should be carried out in various years of study so that the issues discussed could be systematically repeated

3. We should pay particular attention to identifying agonal breaths and all the criteria of quality CPR.

4. It is recommended to perform more detailed analysis to assess students of various directions.

5. The greatest attention should be given to students of the Faculty of Pharmacy and Medical Faculty II.

\section{Acknowledgements}

\section{Conflict of interest statement}

The authors declare no conflict of interest.

\section{Funding sources}

There are no sources of funding to declare.

\section{References}

1. On the basis of: Basic information about the demographic development of Poland to. 2014 year, from http://stat.gov.pl/obszary-tematyczne/ludnosc/ludnosc/ podstawowe-informacje-o-rozwoju-demograficznym-polski-do-2014-roku,12,5.html. Access: 3.01.2016.

2. Kozłowski D, Kłosiewicz T, Kowalczyk A, Kowalczyk AK, Koźluk E, Dudziak M, Homenda W, Raczak G. The knowledge of public access to defibrillation in selected cities in Poland. Arch Med Sci. 2013;9(1):27-33.

3. Grześkowaik M, Pytliński A, Frydrysiak K. Wiedza społeczeństwa Wielkopolski na temat resuscytacji. Nowiny Lekarskie. 2008;77(1):19-24.

4. Skitek I, Witt M, Goniewicz M. Ocena znajomości zagadnień z pierwszej pomocy wśród studentów uczelni uniwersyteckich miasta Poznania. Nowiny Lekarskie. 2012;81(6):641-646.

5. Nolan JP, Soar J, Zideman DA, Biarent D, Bosaert LL, Deakin Ch, et al. Podsumowanie Komitetu Wykonawczego ERC. In: Anders J. (ed.). Wytyczne resuscytacji. Wydawnictwo Fall, Kraków, 2010; 12-13.

6. Lesnik D, Lesnik B, Golub J, Krizmaric M, Mally S, Grmec S. Impact of additional module training on the level of basic life support knowledge of first year students at the University of Maribor. Int J Emerg Med. 2011;19(4):16.

7. Christopher MS, Gavin DP, Ian B, Julian FB. Undergraduate training in the care of the acutely ill patient: a literature review. Intensive Care Med. 2007;33(5):901-7.

8. Woollard M, Whitfield R, Newcombe RG, Colquhoun $M$, Vetter N, Chamberlain D. Optimal refresher training intervals for AED and CPR skills: a randomised controlled trial. Resuscitation. 2006;71(2):237-47.

9. Mani G, Annadurai K, Danasekaran R, Ramasamy JD. A cross-sectional study to assess knpwledge and attitu- des related to Basic Life Support among undergraduated medical students in Tamil Nadu, India. Prog Health Sci. 2014;4(1):47-52.

10. Pilip S, Wójcik A, Michalak G, Gałązkowski R. Wiedza w zakresie resuscytacji krążeniowo-oddechowej u osób zatrudnionych w wybranych jednostkach współpracujących z systemem państwowego ratownictwa medycznego. BiTP. 2015;38(2):133-140.

11. Alanazi A, Alsalmeh $M$, Alsomali $O$, Maged Almurshdi A, Alabdali A, Al-Sulami M, et al. Poor Basic Life Support Awareness among Medical and College of Applied Medical Sciences Students Necessitates the Need for Improvement in Standards of BLS Training and Assessment for Future Health Care Providers. Middle East J Sci Res. 2014;21(5):848-854.

12. Olejniczak D, Miciuk D, Religioni U. Ocena stanu wiedzy studentów Warszawskiego Uniwersytetu Medycznego na kierunku pielęgniarstwo na temat udzielania pierwszej pomocy przedmedycznej. Piel Zdr Publ. 2013;3(2):101110.

13. Burkhardt JN, Glick JE, Terndrup TE, Effect of Prior Cardiopulmonary Resuscitation Knowledge on Compression Performance by Hospital Providers. West J Emerg Med. 2014;15(4):404-408.

14. Chew KS, Mohd Hashairi F, Ida Zarina Z, Shaik Farid AW, Abu Yazid MN, Nik Hisamuddin NAR. A Survey on The Knowledge, Attitude and Confidence Level of Adult Cardiopulmonary Resuscitation Among Junior Doctors in Hospital Universiti Sains Malaysia and Hospital Raja Perempuan Zainab II, Kota Bharu, Kelantan, Malaysia. Med J Malaysia. 2011; 66(1):56-59.

15. Owojuyigbe AM, Adenekan AT, Faponle AF, Olateju SO. Impact of basic life support training on the knowledge of basic life support in a group of Nigerian Dental Students. Niger Postgrad Med J. 2015;22:164-168.

16. Champerek E, Goniewicz M, Włoszczak-Szubzda A, Wac-Górczyńska M, Nowicki G, Mikuła-Mazurkiewicz A. Poziom wiedzy uczniów szkół ponadgimnazjalnych i studentów w zakresie pierwszej pomocy. MONZ. 2011;17(4):174-179.

Acceptance for editing: 2016-03-15 Acceptance for publication: 2016-03-31

Correspondence address: Tomasz Kłosiewicz Department of Rescue and Disaster Medicine, Poznan University of Medical Sciences 79 Dąbrowskiego Str., 60-529 Poznan, Poland phone: +48668956969 e-mail: klosiewicz.tomek@gmail.com 